Revista Destaques Acadêmicos, Lajeado, v. 11, n. 4, 2019. ISSN 2176-3070

DOI: http://dx.doi.org/10.22410/issn.2176-3070.v11i4a2019.2320

http://www.univates.br/revistas

\title{
AVALIAÇÃO DO DESEMPENHO DE SISTEMAS DE TRATAMENTO DE EFLUENTE SANITÁRIO IMPLANTADOS NO MUNICÍPIO DE ESTRELA - RS
}

\author{
Martina Brönstrup ${ }^{1}$
}

Resumo: O descaso com o Saneamento Básico, gera impacto principalmente nos serviços de acesso à água potável, e à coleta e tratamento de efluentes sanitários. Um dos principais problemas em decorrência da crescente urbanização, é o lançamento de esgoto sem prévio tratamento, em particular em mananciais de abastecimento de água da cidade. $\mathrm{O}$ investimento neste âmbito ainda é insatisfatório, embora existam alternativas e tecnologias eficientes e com custos acessíveis para estas situações. O esgoto doméstico é constituído basicamente $99,9 \%$ de água e 0,1\% de sólidos, e é por causa destes sólidos que se torna inevitável o tratamento do esgoto. Existem diferentes níveis de tratamento dos esgotos e são classificados em preliminar, primário, secundário e terciário. Entre os principais parâmetros que merecem destaque são os sólidos indicadores de matéria orgânica, Nitrogênio, Fósforo e os indicadores de contaminação fecal. No município de Estrela, foi avaliada a eficiência das estações de tratamento de efluentes através de análises de DBO5, DQO, sólidos suspensos totais, Fósforo, Nitrogênio e coliformes termotolerantes. Basicamente o método de tratamento de todos os sistemas existentes são anaeróbios. Os resultados não foram satisfatórios, pois não atenderam a todos os parâmetros exigidos pela Resolução 355/2017 do CONSEMA, principalmente na remoção de Nitrogênio, Fósforo e patogênicos. Como alternativa para aumentar a eficiência, é recomendado pós-tratamento de efluentes na remoção de nutrientes, como Nitrogênio e Fósforo, e também na remoção de agentes patogênicos.

Palavras-chave: Saneamento Básico. Esgoto doméstico. Níveis de tratamento. Reatores Anaeróbios. Remoção de nutrientes.

\section{INTRODUÇÃO}

O saneamento surgiu como forma de proteger a saúde do homem, intervindo no meio ambiente. Ações constituídas por uma infraestrutura física e estrutura educacional, que relacionadas ao abastecimento de água potável a população, drenagem de águas pluviais, controle de inundações, coleta e

1 Arquiteta e Urbanista, graduanda do curso Pós-Graduação Lato Sensu - Especialização em Construção Civil, da Universidade UNIVATES. e-mail: martina_bronstrup@hotmail.com 
tratamento de esgoto, limpeza urbana, manejo de resíduos sólidos, abrangem qualquer tipo de agente patogênico, visando à saúde das comunidades (GUIMARÃES, CARVALHO e SILVA, 2007). Assim sendo, percebemos que saúde e saneamento estão diretamente relacionados.

No Brasil, o saneamento básico é assegurado pela Constituição Federal cuja Lei que o rege é a de $n^{\circ} 11.445 / 2007$, e é estabelecido como conjunto de serviços, infraestrutura e instalações de abastecimento de água, limpeza urbana, manejo de resíduos sólidos, esgotamento sanitário, drenagem urbana (BRASIL, 2007).

Entre os eixos do saneamento, os que geralmente ganham destaque, são os serviços de acesso à água potável e à coleta e tratamento de efluentes sanitários. Estes serviços proporcionam a melhoria na qualidade de vida das pessoas, sobretudo na saúde infantil com redução da mortalidade infantil, melhorias na educação, na expansão do turismo, na valorização dos imóveis, na renda do trabalhador, na despoluição dos rios e preservação dos recursos hídricos (JORDÃO; PESSÔA, 2014).

Em cidades com população de até 20 mil habitantes, o investimento em tratamento de esgoto ainda é insatisfatório, pois possuem poucos recursos. Segundo dados apresentados no Sistema Nacional de Informações sobre Saneamento, não há grandes investimentos em busca de solução para tratamentos de esgoto, embora existam alternativas e tecnologias eficientes e com custos acessíveis para estas situações, apesar da legislação (LOURENÇO, L.S. et al).

De acordo com Jordão e Pessôa (2014), os efluentes sanitários domiciliares são provenientes basicamente de residências, edifícios comerciais, instituições ou outras edificações que tenham instalações de banheiros, lavanderias, cozinhas, ou qualquer dispositivo de utilização da água para fins domésticos, e consistem principalmente da água de banho, urina, fezes, papel, restos de comida, sabão, detergentes, águas de lavagem.

No Brasil apenas $46 \%$ do esgoto coletado é tratado, um índice um pouco mais elevado que o da Região Sul, que é de $44,93 \%$. Já no estado do Rio Grande do Sul, este percentual é quase reduzido à metade, aproximadamente 25,82\% do esgoto passa por tratamento, segundo estudo Panorama Setor Privado No Saneamento 2019.

Os esgotos domésticos são constituídos de aproximadamente 99,9\% de água e os $0,1 \%$ restantes correspondem aos sólidos, que podem ser orgânicos e inorgânicos, suspensos e dissolvidos, assim como microrganismos. E é por causa desses 0,1\% que é indispensável o tratamento de esgoto (BARROS; et al, 2007).

Segundo Von Sperling (2017), existem diferentes níveis de tratamento dos esgotos classificados como tratamento preliminar, tratamento primário, tratamento secundário e tratamento terciário. No tratamento preliminar 
ocorre a eliminação apenas de sólidos grosseiros por mecanismos físicos. No tratamento primário ocorrem a remoção de sólidos sedimentáveis, assim como, a redução parcial da matéria orgânica. No tratamento secundário, prevalecem mecanismos biológicos e abrange a remoção da matéria orgânica e eventualmente nutrientes como Nitrogênio e Fósforo, através de sistemas anaeróbios, aeróbio ou ambos. Finalmente, o tratamento terciário é destinado a remoção de poluentes específicos, muitas vezes tóxicos ou ainda não biodegradáveis.

Para Jordão e Pessoa (2014), o tratamento secundário, permite que o esgoto seja tratado de diversas formas diferentes, tais como, lodos ativados, sistemas alagados construídos (wettlands), fossas sépticas e reatores anaeróbios. A seguir, na tabela 1, estão representados os principais sistemas de tratamento secundário e a funcionalidade de cada um.

Tabela 1: Alternativas e funcionalidades de métodos de tratamento secundário de esgoto.

\begin{tabular}{|l|l|}
\hline \multicolumn{1}{|c|}{$\begin{array}{c}\text { SISTEMAS DE } \\
\text { TRATAMENTO }\end{array}$} & \multicolumn{1}{c|}{ METODOLOGIA DE TRATAMENTO } \\
\hline $\begin{array}{l}\text { Lodos ativados - } \\
\text { Consiste sobretudo na } \\
\text { oxidação da matéria } \\
\text { orgânica por meio de } \\
\text { bactérias aeróbias. }\end{array}$ & $\begin{array}{l}\text { Os flocos produzidos no esgoto bruto ou decantado pelo } \\
\text { crescimento de bactérias zoogleias ou outros organismos, } \\
\text { na presença de oxigênio dissolvido e acumulado em } \\
\text { concentração suficiente graças ao retorno de outros } \\
\text { flocos previamente formados. Nele o esgoto afluente e } \\
\text { o lodo ativado são intimamente misturados, agitados e } \\
\text { aerados (em unidades chamadas tanques de aeração), } \\
\text { para logo após se separar os lodos ativados do esgoto (por } \\
\text { sedimentação em decantadores). A maior parte do lodo } \\
\text { ativado assim separado retorna para o processo, enquanto } \\
\text { uma parcela menor é retirada para tratamento específico } \\
\text { ou destino final, o chamado lodo em excesso. }\end{array}$ \\
\hline Fossa séptica & $\begin{array}{l}\text { Pode ser definida como uma câmara convenientemente } \\
\text { construída para reter os esgotos sanitários por um período } \\
\text { de tempo criteriosamente estabelecido, de modo a permitir } \\
\text { a sedimentação dos sólidos e a retenção do material graxo } \\
\text { contido nos esgotos, transformando-os bioquimicamente } \\
\text { em substâncias e compostos mais simples e estáveis. }\end{array}$ \\
\hline
\end{tabular}




\begin{tabular}{|c|c|}
\hline $\begin{array}{c}\text { SISTEMAS DE } \\
\text { TRATAMENTO }\end{array}$ & METODOLOGIA DE TRATAMENTO \\
\hline $\begin{array}{l}\text { Reator anaeróbio de } \\
\text { manta de lodo e fluxo } \\
\text { ascendente ou UASB } \\
\text { (Upflow Anaerobic Sludge } \\
\text { Blanket), RAFA, DAFA } \\
\text { - É um reator anaeróbio } \\
\text { de fluxo líquido } \\
\text { ascendente. }\end{array}$ & $\begin{array}{l}\text { O fluxo do líquido é ascendente. A parte superior do } \\
\text { reator é dividida nas zonas de sedimentação e de coleta } \\
\text { de gás. A zona de sedimentação permite a saída do } \\
\text { efluente clarificado e o retorno dos sólidos (biomassa) ao } \\
\text { sistema, aumentando a sua concentração no reator. Entre } \\
\text { os gases formados inclui-se o metano. O sistema dispensa } \\
\text { decantação primária. A produção do lodo é baixa, e o lodo } \\
\text { já sai adensado. }\end{array}$ \\
\hline
\end{tabular}

Fonte: Von Sperling (2017) e Jordão e Pessoa (2014), adaptado pela autora (2019)

Segundo Von Sperling (2017), "os principais parâmetros relativos a esgotos predominantemente domésticos a merecerem destaque especial face à sua importância são: sólidos, indicadores de matéria orgânica, Nitrogênio, Fósforo e indicadores de contaminação fecal".

$\mathrm{O}$ excesso de Fósforo $(\mathrm{P})$ e o Nitrogênio $(\mathrm{N})$ pode provocar os processos de eutrofização dos recursos hídricos ao impactar, de maneira direta, nos parâmetros físicos, químicos e biológicos das águas, impossibilitando se uso para consumo e lazer. São consequências dos constituintes do efluente sanitário (FREITAS, et al, 2016).

O lançamento de esgoto sanitário no Rio Grande do Sul, está regrado pela Fundação Estadual de Proteção Ambiental - FEPAM, através da DIRETRIZ TÉCNICA N ${ }^{\circ} 05 / 2017$ e Portaria N. ${ }^{\circ}$ 68/2019, que aponta 8 alternativas de tratamento que devem ser previstas pela inciativa privada, e devem ser descartadas nos corpos hídricos receptores (fase líquida), aterro sanitário ou outra aplicação específica (fase sólida), sem prejuízo ao meio ambiente, atendendo aos padrões de lançamento em atendimento da Resolução CONSEMA n ${ }^{\circ}$ 355/2017 e da Resolução CONAMA n n 430/2011.

A partir de 2014, o município de Estrela sancionou uma Lei, que exige a doação de uma área e implantação de uma estação de tratamento de esgoto coletivo a cada novo loteamento urbano que venha a ser executado, cabendo a Prefeitura a responsabilidade pela manutenção destes sistemas (Art. 13, Lei Municipal 6.319, 2014). Esta exigência surgiu de uma crescente necessidade em solucionar de forma definitiva, a constante demanda de efluentes não tratados a cursos hídricos (Secretaria Municipal do Meio Ambiente e Saneamento Básico de Estrela, 2019).

Diante deste cenário, o presente trabalho tem como objetivo conhecer os sistemas implementados pela iniciativa pública no município de Estrela, e a eficiência atingida pela metodologia proposta, além de comparar com outros sistemas alternativos e a possibilidade de aumento na eficácia dos processos. 


\section{MATERIAIS E MÉTODOS}

A metodologia utilizada no referido trabalho, foi baseada em pesquisas bibliográficas em artigos, livros, legislações, periódicos e outras publicações relacionadas ao assunto. Fez-se também o uso de entrevistas informais ao corpo técnico do setor competente, com o intuito de fazer um levantamento prévio das condições de tratamento e disposição final dos efluentes.

Foram feitas visitas in loco para conhecer os sistemas de tratamento de efluentes sanitários implantados no município de Estrela, bem como levantamentos fotográficos, para melhor compreensão do funcionamento dos sistemas. Após, foram compilados os resultados.

Através do relatório de acompanhamento e monitoria das estações de tratamento de esgoto doméstico foi possível compreender melhor os sistemas implementados, no qual podemos verificar a localização, população atendida por cada uma das ETE's, bem como os diferentes níveis de tratamento do efluente bruto.

Também foi feito o levantamento das análises de Demanda Bioquímica de Oxigênios $\left(\mathrm{DBO}_{s}\right)$, série de sólidos dissolvidos e suspensos (sólidos sedimentáveis, Sólidos Suspensos Totais - SST), Fósforo Total, Nitrogênio Amoniacal, Coliformes Termotolerantes, óleos e graxas (totais), do efluente bruto e do efluente tratado, por Laboratório certificado pelo INMETRO e credenciado pela FEPAM.

A análise comparativa de dados para avaliar a eficiência dos sistemas, se deu através do confronto de informações contidas nos resultados do monitoramento contínuo realizado pelo município, através de análises físicoquímicas periódicas e os parâmetros exigidos pela Resolução do CONSEMA $n^{\circ}$ 355/2017.

Feito o levantamento da situação atual das ETE's, foram diagnosticados alguns aspectos que se mostraram ineficientes. Esse diagnóstico se deu através de análise comparativa com o que está estabelecido pela legislação.

A fim de aprimorar estes sistemas de tratamento de efluentes domésticos buscou-se por meio de referências bibliográficas e consultas a trabalhos técnicos soluções visando atender aos parâmetros estabelecidos no lançamento do efluente tratado ao corpo hídrico.

\section{RESULTADOS E DISCUSSÃO}

Segundo dados fornecidos pela Secretaria Municipal do Meio Ambiente e Saneamento Básico do município de Estrela, existem atualmente seis Estações de Tratamento de Esgotos (ETE's) em funcionamento, as quais distribuem-se entre os bairros Auxiliadora (ETE AUXILIADORA), Boa União (ETE NOVA MORADA), Centro (ETE CENTRO), Cristo Rei (ETE CRISTO REI) e Imigrantes (ETE EIDT e GUINTER), enumeradas e demarcadas territorialmente na figura 1. 
Figura 1: ETE’s no município de Estrela

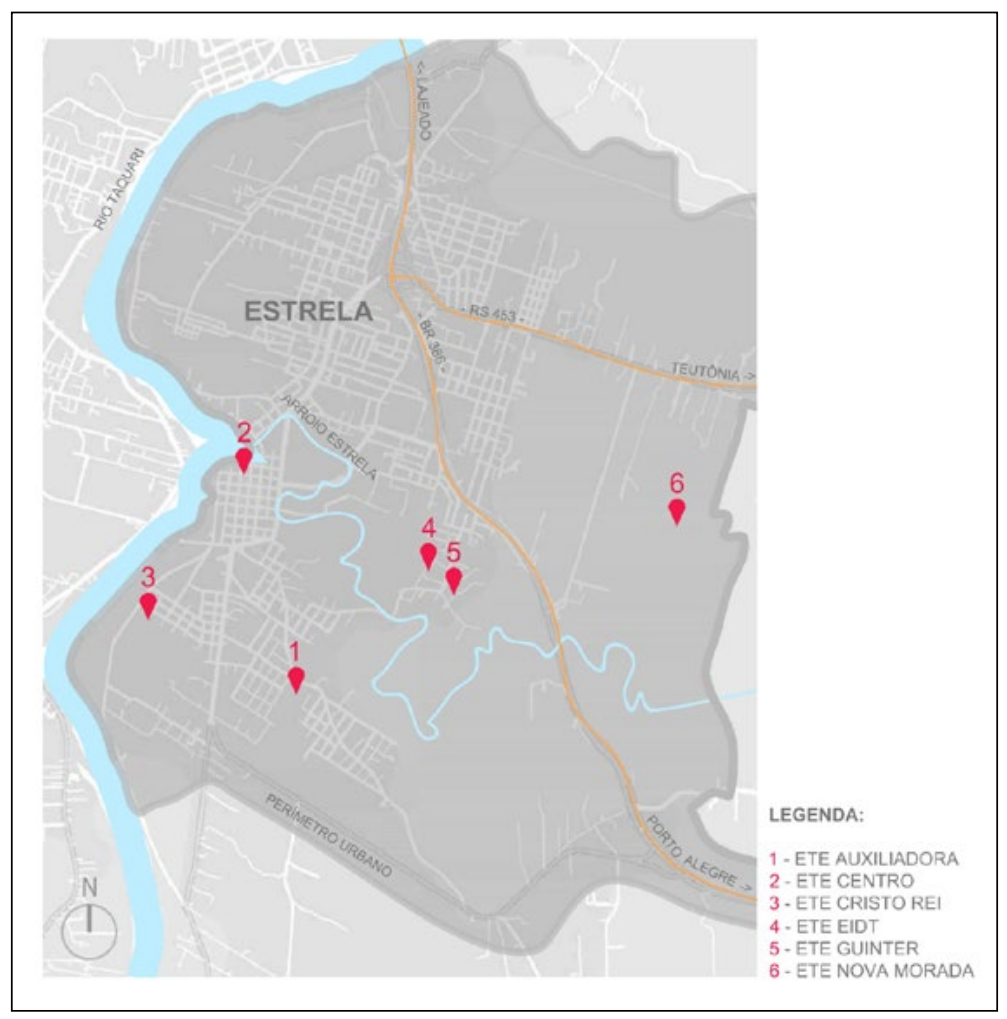

Fonte: Mapa elaborado pela autora, com dados da Secretaria Municipal do Meio Ambiente e Saneamento Básico de Estrela. 2019

Na tabela 2, podemos verificas as unidades das ETE's, bem como os sistemas de tratamento.

Tabela 2: ETE's e sistemas de tratamento

\begin{tabular}{|c|c|c|c|c|c|c|c|c|}
\hline \multirow{3}{*}{\multicolumn{2}{|c|}{$\begin{array}{l}\text { ESTACĀO DE } \\
\text { TRATAMENTO DE } \\
\text { ESGOTO-ETE }\end{array}$}} & \multirow{4}{*}{$\begin{array}{l}\text { NÜMERO DE } \\
\text { RESIDÊNCIAS } \\
\text { ATENDIDAS } \\
50\end{array}$} & \multicolumn{6}{|c|}{ TRATAMENTO } \\
\hline & & & \multicolumn{2}{|c|}{ PREL IMINAR } & \multicolumn{2}{|c|}{ SECUNDÁRIO } & \multicolumn{2}{|c|}{ IERCIÁRIO } \\
\hline & & & Decantaçäo & $\begin{array}{c}\text { Gradeamento } \\
\text { Desarenado }\end{array}$ & Reator Anaeróbıo & Filtro Anaeróbio & Cloraçảo & Wetland \\
\hline 1 & AUXXII IADORA & & $x$ & & $\mathrm{x}$ & $\mathrm{x}$ & & $x$ \\
\hline 2 & CENIRO & 50 & $x$ & & $\mathrm{x}$ & $\mathrm{x}$ & & \\
\hline 3 & CRISIO REI & 50 & $x$ & & $\mathrm{x}$ & $x$ & & \\
\hline 4 & EIDT & 50 & $x$ & & $x$ & $x$ & & $\mathrm{x}$ \\
\hline 5 & GUINTER & 50 & $\mathrm{X}$ & & $\mathrm{X}$ & $\mathrm{x}$ & $\mathrm{X}$ & \\
\hline 6 & NOVA MORADA & 110 & & $\mathrm{X}$ & $\mathrm{x}$ & $\mathrm{x}$ & $\mathrm{X}$ & \\
\hline
\end{tabular}

Fonte: Secretaria Municipal do Meio Ambiente e Saneamento Básico de Estrela, adaptado pela autora. 2019 
Basicamente o método de tratamento de todos os sistemas existentes são anaeróbios (microrganismos anaeróbios). Os sistemas contam com tratamento preliminar, com gradeamento, tratamento secundário em reatores anaeróbios onde ocorre a remoção de matéria orgânica carbonácea, nitrificação e desnitrificação e finalmente, tratamento terciário com desinfecção por reação química.

Em média, a população atendida é de 50 famílias por cada unidade de ETE, com exceção da NOVA MORADA - conjunto habitacional implantado por meio do Programa Minha Casa Minha Vida, na cidade de Estrela -, que atende 110 famílias.

Para verificar a eficiência dos sistemas adotados, os parâmetros analisados foram comparados aos padrões estabelecidos na Resolução do CONSEMA Nº 355/2017. Na tabela 3, encontram-se os resultados das análises dos efluentes tratados, por unidade implantada e a respectiva eficiência.

As coletas das análises dos parâmetros de qualidade dos afluentes e efluentes das ETE's são trimestrais, realizadas por laboratório certificado pelo INMETRO e credenciados pela FEPAM. Os dados apresentados na Tabela 3, são de janeiro de 2019, onde foram analisados parâmetros físicoquímicos e microbiológicos como: Demanda Bioquímica de Oxigênios $\left(\mathrm{DBO}_{5}\right)$, série de sólidos dissolvidos e suspensos (sólidos sedimentáveis, Sólidos Suspensos Totais - SST), Fósforo Total, Nitrogênio Amoniacal, Coliformes Termotolerantes, óleos e graxas (totais). A Demanda Química de Oxigênio (DQO), não é um parâmetro analisado pelo município. Segundo Von Sperling (2017), o parâmetro não é usual para avaliação da eficiência de esgotos tratados.

Tabela 3: Análise dos resultados seguindo a Resolução 355/2017 do CONSEMA

\begin{tabular}{|c|c|c|c|c|c|c|c|c|c|c|c|c|c|c|}
\hline \multirow{2}{*}{\multicolumn{3}{|c|}{$\begin{array}{c}\text { PARÁMETRO CONSIDERANDO A } \\
\text { FADXA DE VAZÄO DO EFLUENTE } \\
Q<100\left(\mathrm{~m}^{2} / d\right)\end{array}$}} & \multicolumn{12}{|c|}{ ESTAÇÁO DE TRATAMENTO DE ESGOTO - ETE } \\
\hline & & & \multirow[t]{2}{*}{1} & \multirow{2}{*}{$\frac{\text { AUXILADORA }}{32,5}$} & \multirow[t]{2}{*}{2} & \multirow{2}{*}{$\begin{array}{l}\text { CENTRO } \\
29\end{array}$} & \multirow{2}{*}{\multicolumn{2}{|c|}{$\begin{array}{c}3 \text { CRISTO REI } \\
5\end{array}$}} & \multirow{2}{*}{4} & \multirow{2}{*}{$\frac{\text { EIDT }}{36,3}$} & \multirow[t]{2}{*}{5} & \multirow{2}{*}{$\begin{array}{l}\text { GUINTER } \\
10\end{array}$} & \multirow{2}{*}{6} & \multirow{2}{*}{$\begin{array}{c}\text { NOVA MORADA } \\
400\end{array}$} \\
\hline DBO, & $(m g l)$ & 120 & & & & & & & & & & & & \\
\hline DCO & $(\mathrm{mgl})$ & 330 & \multicolumn{12}{|c|}{ INEXISTENTE NA ANALISE } \\
\hline SST & $(\mathrm{mgl})$ & 140 & & 28 & & 140 & & 13 & & 86 & & 14 & & 204 \\
\hline \multirow{2}{*}{ Fóstoro Total } & (mgl) & 4 & & 1,5742 & & 2,8237 & & 0,6071 & & 3,7119 & & 1,7463 & & 14,6188 \\
\hline & Eficiência & $75 \%$ & & $-4,27 \%$ & & $44,66 \%$ & & 83,82 & & $28,85 \%$ & & 75,98 & & 5,93 \\
\hline Nitrogénio Amoniacal & $(m g h)$ & 20 & & 13 & & 37 & & 5 & & 35 & & 22 & & 98 \\
\hline \multirow{2}{*}{$\begin{array}{l}\text { Colformes } \\
\text { Termotolerantes }\end{array}$} & NMP $100 \mathrm{~mL}$ & $10^{5}$ & & 240.000 & & 240000 & & 240000 & & 240.000 & & 240.000 & & 240000 \\
\hline & Eficiencia & $95 \%$ & & $0 \%$ & & $0 \%$ & & $0 \%$ & & $0 \%$ & & $0 \%$ & & $0 \%$ \\
\hline
\end{tabular}

LEGENDA ATENDE INEXSTENTE NA ANALISE NÅO ATENDE

Fonte: Secretaria Municipal do Meio Ambiente Saneamento Básico de Estrela, CONSEMA e NBR 7229/1993, adaptado pela autora. 2019 
Para o parâmetro Coliformes Termotolerantes, a eficiência em todos os tratamentos, estão abaixo de $95 \%$, e consequentemente, não atendem aos parâmetros estabelecidos pela Resolução CONSEMA n 355/2017.

Para a remoção de matéria orgânica em termos de demanda bioquímica de oxigênio ${ }_{5}\left(\mathrm{DBO}_{5}\right.$ ) e de sólidos suspensos totais (SST), o sistema implantado atendeu aos parâmetros em quase em todas as ETE's.

O parâmetro Fósforo Total não deve exceder $4 \mathrm{mg} / 1$ para vazões de efluentes tratados inferiores a $100 \mathrm{~m}^{3} /$ dia. Desta forma, a estação de tratamento NOVA MORADA não atende aos padrões de lançamento. Além disso, a eficiência do sistema para remoção de Fósforo Total é inferior a 75\% nas unidades AUXILIADORA, CENTRO, EIDT e NOVA MORADA atingindo nessas estações de tratamento uma eficiência máxima de $44 \%$. Apenas nas ETE's CRISTO REI e GUINTER, os parâmetros eficiência se enquadram nos valores estabelecidos pela Resolução 355/2017 do CONSEMA.

O parâmetro Nitrogênio Amoniacal, aponta em quase todas as ETE's para valores acima dos estabelecidos, e consequentemente a ineficiência do sistema com este padrão. As exceções são as ETE's AUXILIADORA e CRISTO REI.

As ETE CRISTO REI foi a que apresentou melhor desempenho, mas ainda assim não atende a todos os parâmetros. Em seguida vem a ETE GUINTER. Já a ETE NOVA MORADA, não atende a nenhum dos requisitos estabelecidos pela legislação.

Comparando os valores de entrada do efluente bruto e a saída do efluente tratado de todas as ETE's, a eficiência na redução de carga dos poluentes é deficiente, principalmente na remoção de Nitrogênio Amoniacal, Fósforo Total e patogênicos, pois deveriam atender a todos os parâmetros exigidos pela legislação. Dependendo da quantidade em que estes nutrientes (nitratos, fosfatos) são lançados no corpo hídrico receptor, pode ocorrer um processo chamado eutrofização - crescimento excessivo de plantas aquáticas -, o que dificulta a passagem de luz e a dissolução de oxigênio (FREITAS, et al, 2016). É necessária a remoção intencional de nutrientes, para contribuir para a melhoria na funcionalidade da ETE. Uma alternativa bastante promissora para o aumento da eficiência destes sistemas, é a adoção de forma de pós-tratamento de efluentes de reatores anaeróbios.

Considerando que o formato dos sistemas apresentados são anaeróbios, é bem provável que por não haver condições aeróbicas no processo, não ocorre a nitrificação, onde a amônia é oxidada a nitrito e o nitrito é oxidado a nitrato (METCALF \& EDDY, 2003 apud ZOPPAS, BERNARDES e MENEGUZZI, 2016). E, então, sob condições anóxicas esta amônia oxidada seria transformada em nitrogênio gasoso (CHANG et al, 2011; MUÑOZ et al.,2009 apud ZOPPAS, BERNARDES e MENEGUZZI, 2016). 
O sistema de lodos ativados tem ganhado bastante destaque, pois apresentou desempenho satisfatório na remoção biológica de nutrientes. A transformação de amônia em nitrato (nitrificação), onde ocorre a retirada da amônia, mas não do Nitrogênio. Bactérias que atuam na ausência de oxigênio e se utilizam de nitratos no seu processo respiratório são responsáveis pela conversão deste Nitrogênio para a forma gasosa (desnitrificação) que é lançada na atmosfera (VON SPERLING, 2002).

Para a remoção do Fósforo é indispensável a existência de zonas anaeróbias e zonas aeróbias, onde, nestes ambientes alternados algumas bactérias são capazes de absorver o Fósforo em grande quantidade, mais do que é necessário para o seu metabolismo. Estas bactérias ficam retidas no lodo excedente que será removido (VON SPERLING, 2002).

Outra opção associada ao pré-tratamento anaeróbio seria o emprego das lagoas de polimento, pois mostrou grande eficiência na remoção de patógenos e nutrientes como Nitrogênio e Fósforo do efluente final, em função das condições favoráveis de Ph (CHERNICHARO, 2001).

\section{CONCLUSÃO}

Após todas as análises efetuadas foi possível concluir que, os sistemas implementados pelo município de Estrela, não atendem a todos os padrões de lançamento em todas as unidades das ETE's, e a eficiência dos sistemas encontram-se comprometidas em todas as estações de tratamento implantadas.

Apesar de se reconhecer a alta eficiência dos sistemas anaeróbios na remoção de matéria orgânica em termos de $\mathrm{DBO}_{s}$ e SST, nem sempre a qualidade dos efluentes anaeróbios atendem a legislação ambiental.

As técnicas e processos que vão ser utilizados para o tratamento de efluentes vão ser determinados de acordo com algumas características, de acordo com a área, com os recursos financeiros disponíveis e com o grau de eficiência que se deseja obter na qualidade final do efluente.

\section{REFERÊNCIAS}

ASSOCIAÇÃO BRASILEIRA DE NORMAS TÉCNICAS. NBR 7229: Projeto, construção e operação de sistemas de tanques sépticos. Rio de Janeiro: ABNT, 1993. Disponível em: http:/ /www.abnt.org.br/. Acesso em: 2 jul. 2019.

BRASIL. Constituição (1988). Constituição da República Federativa do Brasil. Disponível em: http:/ /www.planalto.gov.br/ccivil_03/_ato2007-2010/2007/Lei/ L11445.htm. Acesso em: 17 jun. 2019.

BRASIL. Lei $\mathbf{n}^{\mathbf{0}}$. 11.445, de 05 de janeiro de 2007. Estabelece diretrizes nacionais para o saneamento básico; altera as Leis nos 6.766, de 19 de dezembro de 1979, 8.036, de 11 de maio de 1990, 8.666, de 21 de junho de 1993, 8.987, de 13 de fevereiro de 1995; revoga a 
Lei no 6.528, de 11 de maio de 1978; e dá outras providências. Disponível em: http:/ / www.planalto.gov.br/ccivil_03/_ato2007-2010/2007/Lei/L11445.htm. Acesso em: 17 jun. 2019.

BRASIL. Lei $\mathbf{n}^{\mathbf{0}} \mathbf{. 6 . 3 1 9}$, de 29 de abril de 2014. Acrescenta dispositivos à Lei Municipal $\mathrm{n}^{\circ} 1.621$, de 28 de dezembro de 1979, que dispões sobre loteamentos e dá outras providências. Disponível em: https:/ / estrela.atende.net/?pg=autoatendimento\#!/ tipo/servico/valor/92/padrao/1/load/1. Acesso em: 17 jun. 2019.

BARROS, Raphael Tobias de Vasconcelos; CHERNICHARO, Carlos Augusto de Lemos; HELLER, Léo. Manual de saneamento e proteção ambiental para os municípios. Saneamento. vol. 2, 5. ed. Belo Horizonte: DESA/UFMG, 2007. 221 p.

CHEMIN, Beatris F. Manual da Univates para trabalhos acadêmicos: planejamento, elaboração e apresentação. 3. ed. Lajeado: Univates, 2015. 315 p.

CHERNICHARO, Carlos Augusto Lemos. Pós-tratamento de efluentes de reatores anaeróbicos: coletânea de trabalhos técnicos. vol. 2. Belo Horizonte: Segrac, 2001. $272 \mathrm{p}$.

CONSELHO ESTADUAL DO MEIO AMBIENTE - CONSEMA. Resolução 355/2017: Dispõe sobre os critérios e padrões de emissão de efluentes líquidos para as fontes geradoras que lancem seus efluentes em águas superficiais no Estado do Rio Grande do Sul. Publicado no DOE do dia 19/07/2017. 7p. Disponível em: https:/ / www.sema. rs.gov.br/resolucoes. Acesso em: 19 jun. 2019.

CONSELHO NACIONAL DO MEIO AMBIENTE-CONAMA. Resolução 430/2011: Dispõe sobre as condições e padrões de lançamento de efluentes, complementa e altera a Resolução no 357, de 17 de março de 2005. 13 de maio de 2011 9p. Disponível em: http:/ / www2.mma.gov.br/port/conama/legiabre.cfm?codlegi=646. Acesso em: 19 jun. 2019.

FUNDAÇÃO ESTADUAL DE PROTEÇÃO AMBIENTAL HENRIQUE LUIZ ROESSLER - FEPAM. Diretriz Técnica Nº 05/2017: diretriz técnica referente ao descarte e ao reuso de efluentes líquidos no âmbito do Estado do Rio Grande do Sul. 12 abr. 2017. Disponível em: http:/ / www.fepam.rs.gov.br/CENTRAL/DIRETRIZES/ DT-005-2017.PDF. Acesso em: 2 jul. 2019.

FUNDAÇÃO ESTADUAL DE PROTEÇÃO AMBIENTAL HENRIQUE LUIZ ROESSLER - FEPAM. Portaria Nº 68/2019: dispõe sobre os critérios para disposição final de efluentes líquidos sanitários e efluentes líquidos industriais em solo no Estado do Rio Grande do Sul. 15 jul. 2019. Disponível em: http:/ / www.fepam.rs.gov.br/ LEGISLACAO/ARQ/PORTARIA068-2019.PDF. Acesso em: 24 jul. 2019.

FREITAS, G. P.; RIBEIRO, R. B. S.; SILVA, K. A.; CAVALCANTI, I. L. R.. Sistema de tratamento de efluentes para o campus da Universidade Federal de Campina Grande na cidade de Pombal. REVISTA VERDE DE AGROECOLOGIA E DESENVOLVIMENTO SUSTENTÁVEL, v. 11, p. 8-12-12, 2016. Disponível em: 
https:/ / editoraverde.org/gvaa.com.br/revista/index.php/RVADS/article/ view/4525/3873. Acesso em: 17 jun. 2019.

GOVERNO DO MUNICÍPIO DE ESTRELA, Secretaria Municipal do Meio Ambiente e Saneamento Básico de Estrela - SEMA. 2019

GUIMARÃES, A. J. A.; CARVALHO, D. F.; SILVA, L. D. B. Saneamento básico, ago. 2007. Disponível em: https:/ / www.ebah.com.br/content/ABAAABwH8AG/ capitulo1-saneamento-basico. Acesso em: 17 jun. 2019.

INSTITUTO TRATA BRASIL - ITB. Estudo: Panorama Setor Privado No Saneamento 2019. Portal Eletrônico. Disponível em: http:/ / www.tratabrasil.org.br/estudos / estudos-itb/outros-estudos. Acesso em: 21 jun. 2019.

JORDÃO, Eduardo Pacheco; PESSÔA, Constantino Arruda. Tratamento de Esgoto Domésticos. 7. ed. Rio de Janeiro: ABES, 2014. 1087 p.

LOURENÇO, Lucas S.; RODRIGUES, Eduardo B.; MOREIRA, Marcelo, A.; SKORONSKI, Everton. Remoção de matéria orgânica e nutrientes de esgoto doméstico por wetland horizontal de fluxo subsuperficial na estação de tratamento de Aparecida - Campos Novos, SC. Revista Brasileira de Agropecuária Sustentável (RBAS), v. 8, n.1, p85-94, mar. 2018. Disponível em: https://periodicos.ufv.br/ojs/rbas/article/ view/3021. Acesso em: 21 jun. 2019.

ORGANIZAÇÃO MUNDIAL DE SAÚDE - OMS. Disponível em: https:/ /www. who.int/. Acesso em: 17 jun. 2019.

VON SPERLING, Marcos. Princípio do Tratamento Biológico de Águas Residuárias -Introdução à qualidade das águas e ao tratamento de esgotos. v. 1. 4. ed. Belo Horizonte: DESA/UFMG, 2017. 452 p.

VON SPERLING, Marcos. Princípio do Tratamento Biológico de Águas Residuárias Lodos ativados. v. 4. 2. ed. Belo Horizonte: Editora UFMG, 2002. 428 p.

ZOPPAS, Fernanda Miranda; BERNARDES, Andrea Moura; MENEGUZZI, Álvaro. Parâmetros operacionais na remoção biológica de nitrogênio de águas por nitrificação e desnitrificação simultânea. Revista Engenharia Sanitária Ambiental, Rio de Janeiro, v. 21, n. 1, p. 29-42, mar. 2016. Disponível em: http:/ / www.scielo.br/scielo. php?script=sci_arttext\&pid=S1413-41522016000100029\&lng=pt\&nrm=iso. Acesso em: 11 dez. 2019. doi: http:/ / dx.doi.org/10.1590/S1413-41520201600100134682 
